\title{
Delaying the COVID-19 epidemic in Australia: evaluating the effectiveness of international travel bans
}

\author{
Adeshina Adekunle, ${ }^{1}$ Michael Meehan, ${ }^{1}$ Diana Rojas-Alvarez, ${ }^{2}$ James Trauer, ${ }^{3}$ Emma McBryde ${ }^{1}$
}

s of 18 March 2020, SARS-CoV-2

has caused almost 200,000 cases of

COVID-19, 8,000 deaths and spread to over 150 countries. ${ }^{1}$ Declared a pandemic on $12 \mathrm{March}^{2}$ it is clear that the world has lost the opportunity to contain the virus SARSCoV-2 as was achieved for SARS-CoV-1.

With 565 confirmed cases ${ }^{3}$ and still counting, COVID-19 now looks certain to cause sustained local transmission within Australia. Therefore, at this time it is reasonable to reflect on the value of travel restrictions imposed to date (China, South Korea, Iran and Italy travel bans were implemented on 31 January, 9 February, 1 March and 11 March, respectively) and to consider the benefit of ongoing travel restrictions in the coming weeks and months, when community transmission starts to increase. We answered these questions using the Official Aviation Guide of the Airways (OAG) travel data and a meta-population model for disease transmission. First we examined what would have happened had the travel ban from Wuhan/China not been implemented. Similarly we examined the impacts of bans to other emerging epicentres, including Iran, Italy, and South Korea. We then examined the implications for the future response and compared the cases expected through community transmission, and from importation over the coming two months.

\begin{abstract}
Objective: Following the outbreak of novel Severe Acute Respiratory Syndrome Coronavirus-2 (SARS-CoV-2), and the disease named COVID-19, in Wuhan, China in late 2019, countries have implemented different interventions such as travel bans to slow the spread of this novel virus. This brief report evaluates the effect of travel bans imposed to prevent COVID-19 importation in the Australian context.

Methods: We developed a stochastic meta-population model to capture the global dynamics and spread of COVID-19. By adjusting our model to capture the travel bans imposed globally and in Australia, the predicted COVID-19 cases imported to Australia were evaluated in comparison to observed imported cases.

Results: Our modelling results closely aligned with observed cases in Australia and elsewhere. We observed a 79\% reduction in COVID-19 importation and a delay of the COVID-19 outbreak in Australia by approximately one month. Further projection of COVID-19 to May 2020 showed spread patterns depending on the basic reproduction number.

Conclusion: Imposing the travel ban was effective in delaying widespread transmission of COVID-19. However, strengthening of the domestic control measures is needed to prevent Australia from becoming another epicentre.

Implications for public health: This report has shown the importance of border closure to pandemic control.

Key words: COVID-19, travel ban, mathematical modelling, basic reproduction number

Methods

To model COVID-19 transmission we used a stochastic meta-population model, which categorises the global population into susceptible, exposed, infectious or removed (SEIR) individuals. Reference 4 gives a detailed definition of a stochastic meta-population model $^{4}$ and the Supporting Information details the full model specification. We parameterised the model to fit with observed case notification reports, ${ }^{5}$ allowing for

non-notified cases. In China, we allowed the reproduction number to be 2.63 from 1 December 2019 until 31 January 2020, at which time extensive intervention measures successfully reduced it to $1.73 .{ }^{6}$ For future predictions, we considered these two values to represent best- and worst-case scenarios applicable to Australia.

Migration patterns in our meta-population model were based on data obtained from OAG on international flight travel volumes for 200 countries in March 2018. From
\end{abstract}

\footnotetext{
1. Australian Institute of Tropical Health and Medicine, James Cook University, Townsville, Queensland

2. College of Public Health, Medical and Veterinary Sciences, James Cook University, Townsville, Queensland

3. School of Public Health and Preventive Medicine, Monash University, Victoria

Correspondence to: Adeshina Adekunle, Australian Institute of Tropical Health and Medicine, James Cook University, Townsville, Queensland 4811;

e-mail: adeshina.adekunle@jcu.edu.au

Submitted: April 2020; Revision requested: May 2020; Accepted: May 2020

The authors have stated they have no conflict of interest.

This is an open access article under the terms of the Creative Commons Attribution-NonCommercial-NoDerivs License, which permits use and distribution in any medium, provided the original work is properly cited, the use is non-commercial and no modifications or adaptations are made.
} 
1 December 2019 until 24 January 2020, we assumed travel proceeded in accordance with these historic travel data. From 24 January, we progressively imposed travel restrictions, as indicated in the International Air Transport Association (IATA) travel information.

We simulated our stochastic meta-population model 1,000 times to generate estimates of: the cumulative number of imported cases in each country and the projected epidemic curves in Australia: both in the presence and absence of travel bans.

\section{Results}

We first validated our model by comparing estimates of imported cases provided by the model simulations with reported values as
Figure 1:Cumulative imported cases of COVID-19 as at January 31, 2020 for the 19 countries. The median cumulative importation and interquartile ranges from 1,000 simulations of the stochastic meta-population model are shown in blue, while the observed imported COVID-19 cases are shown in red for each country.

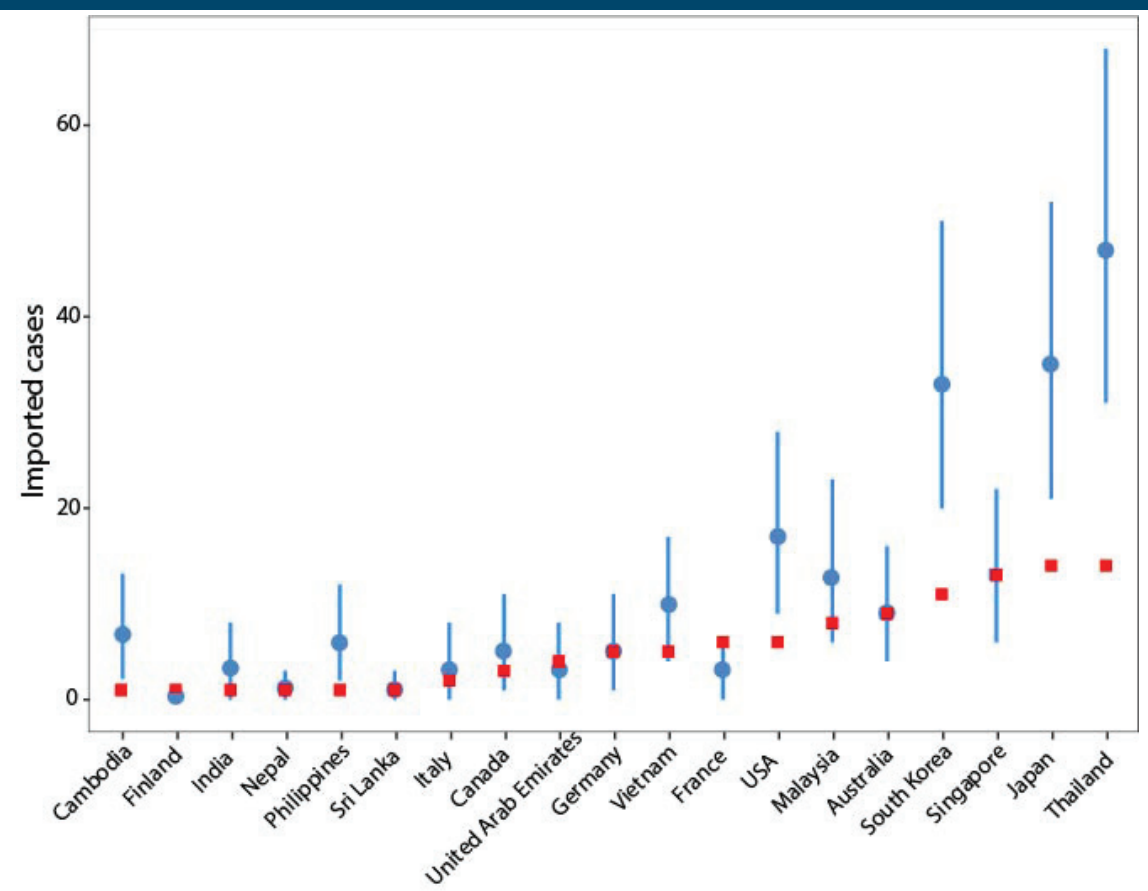

at January 312020 (see Figure 1). We found that our meta-population model accurately reproduced reported observations for many countries - in particular, Australia. However estimates became increasingly unreliable for countries with significant migration volumes with China. Differences between model predictions and observation can be partially accounted for by stochastic variation and potential under-reporting.

Figure 2 shows the predicted number of cases Australia would have received if the ban on travel from China had not occurred. By 2 March 2020, our model estimated that Australia would have received over 70 imported cases of COVID-19 compared with the 15 importations actually observed, representing a $79 \%$ reduction in expected cases, and similar to what was estimated elsewhere. ${ }^{7}$ However, the introduction of travel bans on international passengers arriving from Iran, South Korea and Italy did not lead to a significant decrease in the expected COVID-19 importation count to Australia. One reason for this is the much lower prevalence in these countries compared with China. Furthermore, Italy had already placed itself in lock-down by the time Australia enforced restrictions on travellers arriving from Italy.

We explored the impact of the travel ban on time to widespread local transmission within Australia, and compared this with other interventions such as reducing

Figure 2: Travel Ban effect on COVID-19 importation to Australia. Cumulative importation to Australia in the absence of travel ban (A) and with travel bans (B). The reported imported COVID-19 cases and interquartile ranges from 1000 simulations are also shown for each travel scenario.

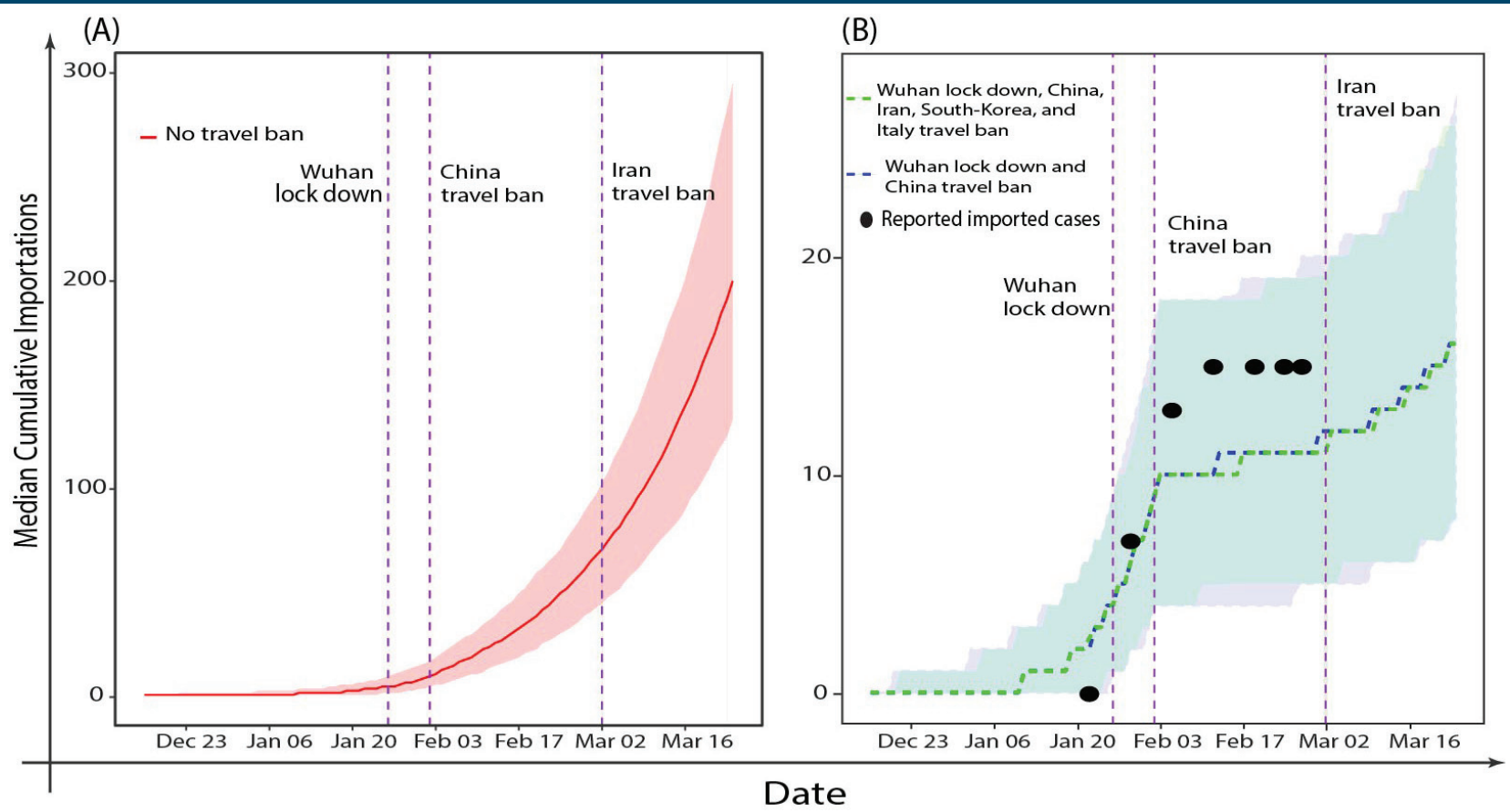


numbers of physical contacts (and thereby reducing the reproduction number). We found that Australia may have experienced local transmission as early as 15 January and without travel bans, could have become the Pacific epicentre by mid-February. However, the China travel ban delayed the widespread occurrence of local transmission by approximately one month (Figure 3 ). If interventions are in place that can reduce the reproduction number to 1.73 (in line with China's response) local transmission could be delayed by a further five weeks. Overlaying the simulation prediction with observed local cases in Australia suggests more needs to be done to slow down the virus in Australia.

\section{Discussion}

After an initial period of inactivity, the governments of many countries have now moved to impose international travel restrictions to prevent further importation of COVID-19 cases. However, given that the virus is now a global pandemic and has reached most countries, it is reasonable to consider the impact of ongoing travel restrictions. In this short communication we integrated international flight data into a model of disease transmission to predict the national epidemic trajectory had travel bans not been put in place. Our results showed that the travel ban on individuals arriving from China successfully delayed the onset of widespread transmission in Australia by approximately four weeks. We also showed that travel bans from Hubei Province alone would have been much less effective, as the virus had already spread to many other provinces by the time the bans were enforced. Similarly, travel bans on arrivals from South Korea and Iran appear to have had a negligible impact. However, as the number of cases in these countries continues to rise, we expect these restrictions to become increasingly effective. Universal international travel bans coming into force now appear to be the only rational response; however, we need to consider how long they can and should last.

Future travel restrictions may have an impact for the next few weeks but potential importations will eventually be overwhelmed by local transmission unless we can effectively control transmission and achieve an effective reproduction number below 1 . We estimate local transmission will outweigh imports sometime in the next two weeks if transmission proceeds at the pace it did in China prior to 21 January ( $\mathrm{R} 0=2.63)$, but will be delayed if Australia can successfully reduce transmission to a level similar to China from January $21(\mathrm{R} 0=1.73)$.

Figure 3: The effects of reduction in transmission rate on the local transmission. The y-axis shows cumulative local cases from our simulations on a log scale (red- no travel ban, green- travel ban and blue - travel ban with reduced transmission rate). The black points are the observed cumulative cases.

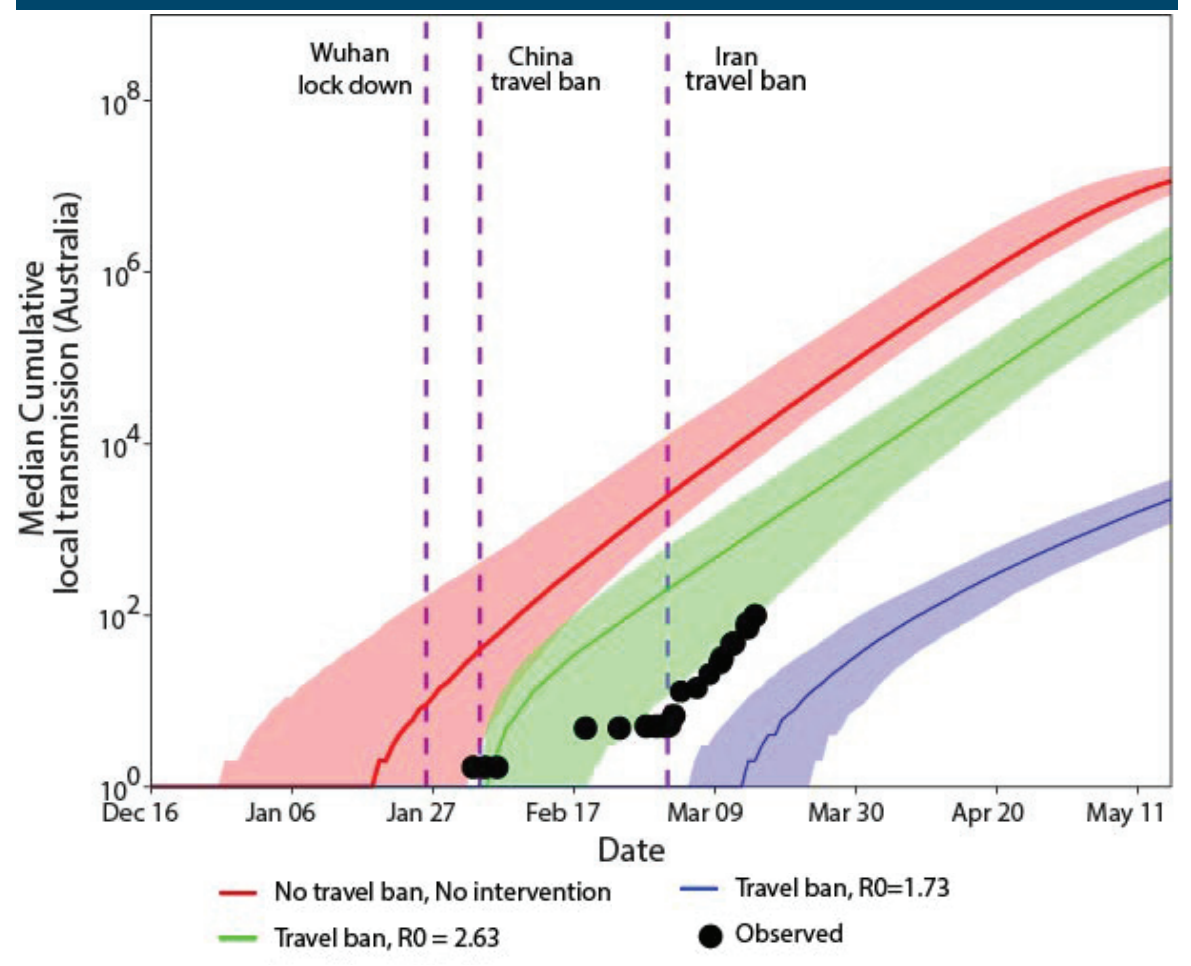

We highlighted the limitations of our study in the Supporting Information.

Given the importance of border closure in delaying outbreaks in the current pandemic, countries should enact real-time data sharing and forecasting for future emerging infectious diseases. Modelling travel-related infection spread and the impact of early border closure should be become routine and has the potential to avert country-level outbreaks.

\section{References}

1. Dong $E$, Du H, Gardner L. An interactive web-based dashboard to track COVID-19 in real time. Lancet Infect Dis. 2020;20(5):533-4.

2. World Health Organization. WHO Director-General's Opening Remarks at the Media Briefing on COVID-19-11 March 2020. Geneva (CHE):WHO; 2020. [cited 2020 Mar 18] Available from: https://www.who.int/dg/speeches/ detail/who-director-general-s-opening-remarks-atthe-media-briefing-on-covid-19---11-march-2020

3. Australian Department of Health. Coronavirus (COVID-19) Current Situation and Case Numbers. Canberra (AUST): Government of Australia; 2020. [cited 2020 March 18] Available from: https://www. health.gov.au/news/health-alerts/novel-coronavirus2019-ncov-health-alert/coronavirus-covid-19-currentsituation-and-case-numbers

4. North AR, Godfray HCJ. The dynamics of disease in a metapopulation: The role of dispersal range. J Theor Biol. 2017;418:57-65.

5. Abbott S, Hellewell J, Munday JD, Young Chun J, Thompson RN, Bosse Nl, et al. Temporal Variation in Transmission During the COVID-19 Outbreak. London (UK): London School of Hygiene and Tropical Medicine Centre for Mathematical Modelling of Infectious Diseases; 2020. [cited 2020 March 20] Available from: https://cmmid.github.io/topics/covid19/ current-patterns-transmission/global-time-varyingtransmission.html

6. Wang H, Wang Z, Dong Y, Chang R, Xu C, Yu X, et al. Phase-adjusted estimation of the number of Coronavirus disease 2019 cases in Wuhan, China. Cell Discov. 2020;6(1):1-8.

7. Anzai A, KobayashiT, Linton NM, Kinoshita R, Hayashi K, Suzuki A, et al. Assessing the impact of reduced travel on exportation dynamics of novel coronavirus infection (COVID-19). J Clin Med. 2020;9(2):601.

\section{Supporting Information}

Additional supporting information may be found in the online version of this article:

Supplementary Appendix 1: Model description. 


\section{University Library}

\section{- M I N E R VA}

\section{A gateway to Melbourne's research publications}

Minerva Access is the Institutional Repository of The University of Melbourne

Author/s:

Adekunle, A;Meehan, M;Rojas-Alvarez, D;Trauer, J;McBryde, E

Title:

Delaying the COVID-19 epidemic in Australia: evaluating the effectiveness of international travel bans

Date:

2020-07-22

\section{Citation:}

Adekunle, A., Meehan, M., Rojas-Alvarez, D., Trauer, J. \& McBryde, E. (2020). Delaying the COVID-19 epidemic in Australia: evaluating the effectiveness of international travel bans. AUSTRALIAN AND NEW ZEALAND JOURNAL OF PUBLIC HEALTH, 44 (4), pp.257-259. https://doi.org/10.1111/1753-6405.13016.

Persistent Link:

http://hdl.handle.net/11343/245058

License:

CC BY-NC-ND 